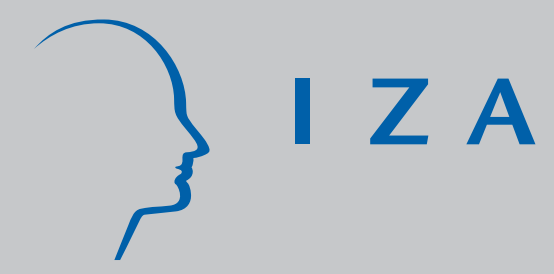

IZADP No. 1679

The Perverse Effects of Partial Employment Protection Reform: Experience Rating and French Older Workers

Luc Behaghel

Bruno Crépon

Béatrice Sédillot

J uly 2005 


\title{
The Perverse Effects of Partial Employment Protection Reform: Experience Rating and French Older Workers
}

\author{
Luc Behaghel
}

LEA-INRA

Bruno Crépon

CREST-INSEE and IZA Bonn

Béatrice Sédillot

DARES

Discussion Paper No. 1679

July 2005

IZA

P.O. Box 7240

53072 Bonn

Germany

Phone: +49-228-3894-0

Fax: +49-228-3894-180

Email: iza@iza.org

\begin{abstract}
Any opinions expressed here are those of the author(s) and not those of the institute. Research disseminated by IZA may include views on policy, but the institute itself takes no institutional policy positions.
\end{abstract}

The Institute for the Study of Labor (IZA) in Bonn is a local and virtual international research center and a place of communication between science, politics and business. IZA is an independent nonprofit company supported by Deutsche Post World Net. The center is associated with the University of Bonn and offers a stimulating research environment through its research networks, research support, and visitors and doctoral programs. IZA engages in (i) original and internationally competitive research in all fields of labor economics, (ii) development of policy concepts, and (iii) dissemination of research results and concepts to the interested public.

IZA Discussion Papers often represent preliminary work and are circulated to encourage discussion. Citation of such a paper should account for its provisional character. A revised version may be available directly from the author. 


\section{ABSTRACT \\ The Perverse Effects of Partial Employment Protection Reform: Experience Rating and French Older Workers*}

French firms laying off workers aged 50 and above have to pay a tax to the unemployment insurance system, known as the Delalande tax. This is an original case of experience rating in the European context, restricted to older workers, whose employment prospects are particularly bad. We evaluate its impact on layoff (firing) as well as on hiring, taking advantage of several changes in the measure since its introduction in 1987. We find particularly strong evidence of an adverse effect of the tax on the firms' propensity to hire older workers, thanks to a legislative change in 1992, when workers hired after the age of 50 stopped being liable for the tax. Chances to find a job increased significantly for unemployed workers older than 50, compared to workers just below 50 who remained liable for the tax. We estimate that before 1992, the tax reduced the probability that an unemployed worker aged 50 find a job by as much as $25 \%$. Evidence on the effect on layoffs is less clear cut. The impact is sizeable only for the most stringent tax schedule, after 1998, but it is also imprecisely estimated.

JEL Classification: J23, J63, J65

Keywords: experience rating, employment protection, older workers, firing, hiring

Corresponding author:

Luc Behaghel

LEA-Inra

42, bvd Jourdan

75014 Paris

France

Email: luc.behaghel@normalesup.org

\footnotetext{
* This work builds upon previous work with Béatrice Sédillot. We are particularly grateful to David Blau, Pierre Cahuc, Thierry Magnac and Thomas Piketty for helpful comments. We also thank seminar participants at CREST, Lunch Seminar Jourdan and at Insee Research Seminar. The usual disclaimer applies.
} 


\section{Introduction}

A key rationale for employment protection is to induce firms to internalize the social cost of unemployment. It underlies the experience-rating feature of the U.S. unemployment insurance (UI) system. But, surprisingly enough, experience rating is rare in countries with the most stringent employment protection, like in Continental Europe. There, employment protection mostly consists of severance payments and advanced notice periods, as well as administrative firing costs (administrative declarations,...). This is puzzling as these forms of employment protection are harder to justify. Severance payments and advanced notice periods can play as an insurance device between the firm and the worker - but in that case, they need not be mandatory and could be let to the initiative of private contracting (Pissarides, 2002). Administrative firing costs appear, at least partly, as a waste of resources: even though they can be grounded on equity purposes, as a way to prevent unjust dismissals, the burden of the cost is high and most likely passed on to the workers in the form of lower wages or of unemployment.

Such considerations have led several economists to advocate the extension of experience rating to Continental Europe (e.g., Blanchard and Tirole, 2003). But, by comparison with the U.S. where its effects have been extensively studied (see Topel, 1983 and 1984; Anderson and Meyer, 1994 and 2000), we lack evidence on the desirability of experience rating in Europe. This is a problem since, as pointed by Cahuc and Malherbet (2004), the effects of experience rating depend on specificities of the labor markets. They argue that the rigidities experienced in several Continental Europe labor markets may affect the efficiency of experience rating in an indeterminate way: on one hand, the preexistence of stringent employment protection may make further increases in the cost of layoffs ineffective and inefficient; but, on the other hand, the existence of a minimum wage, by inducing excess layoffs, may increase the need for incentives in the other direction, hence for experience rating. Another concern, not analyzed by Cahuc and Malherbet (2004), is the fear that firms refrain from hiring populations with higher unemployment risks. This is the usual adverse impact of any measure of employment protection; it may be magnified in markets with high unemployment rates and longer unemployment durations. All in all, can experience rating be effective in reducing excess layoffs in markets already characterized by high employment protection, and can it be done without a strong adverse impact on hiring? These are important issues for which we lack direct empirical evidence in Continental Europe. 
The contribution of this paper is to provide such evidence by studying the impact of the Delalande tax on hiring and layoff (firing). ${ }^{1}$ The Delalande tax is a measure that introduced rough experience rating features in the employment protection of older workers in France, in 1987. Firms laying off a worker aged 50 and above are required to pay a tax to the UI system that is proportional to the worker's gross wages. Besides the fact that it is an exception in the European employment protection landscape, studying the impact of that tax is interesting for several reasons. First, the tax is focused on a group of workers whose employment prospects are particularly bad. The employment rate of French workers aged 55 to 59 fell in the beginning of the eighties and has stabilized below 60\% (for men) since then. Chances to find a job are very low for workers laid off after the age of 50. The rationale for experience rating is therefore particularly compelling, as the firms do not internalize the cost of the resulting unemployment and early retirement spells; on the contrary, early exits after 55 is widely viewed as a consensual way of workforce adjustment (Behaghel and Gautié, 2005). Second, however, the risk of an adverse effect on hiring is particularly acute for older workers, as age discrimination may already exist for that age group. Third, the Delalande tax has undergone several major legislative changes that are particularly appropriate to set up natural experiments in order to study its effects on labor flows (hiring and layoff).

Building on these legislative changes, we separately analyze the effects of the tax on the probability that an older worker is hired and laid off. For hiring, we take advantage of a change that occurred in 1992 and exempts from the tax workers hired after the age of 50, if they are laid off later on. We find that the chances to find a job increased for unemployed workers aged just above 50 relative to those just below 50. The difference-in-difference estimate is sizeable and significant for male unemployed workers, pointing toward a large adverse effect of the tax on hiring. For females, the effect is not significant, which may be explained by the specificities of female labor supply. Our approach of the effect on layoffs is twofold. First, we use three changes in the tax schedule (in 1987, 1992 and 1998) to infer its consequences on layoff rates, using workers in the unprotected age group (below 50) as a control group. Second, we build upon a differentiated change in 1998, as the tax was raised for firms with more than 50 employees and unchanged for those with fewer workers. Our results tend to show that the tax reduced layoffs for older men; however, the estimates remain imprecise and rather small, except for the most stringent tax schedule in 1998.

Besides the literature on experience rating, our paper relates to a handful of recent papers looking for variation in labor legislation across groups of workers in a given country as a way to provide micro, quasi-experimental evidence on the impact of employment protection. Acemoglu and Angrist (2001) look at the effect of the American with

\footnotetext{
${ }^{1}$ Recall layoffs do not exist in France. We will use the word "layoff" for (permanent) redundancies or
} 
Disabilities Act: they find that it reduced the employment rate of the protected group, the disabled workers, most likely through lower hiring rates - but they do not find significant effects on layoffs. Autor, Donohue and Schwab (2002) find that employment of protected groups is ultimately reduced by the adoption of wrongful-discharge laws by various States in the U.S. In Colombia, Kugler (2004) finds that a reduction in dismissal costs increased separations and accessions for formal workers relative to informal workers, and more so in larger firms that were most likely to be affected by the reform. Last, Hakola and Uusitalo (2005) study the impact of the experience rating of unemployment pension benefits in Finland, using a 2000 reform that affected firms differently depending on their size. They find that layoffs are sensitive to the degree of experience rating; but they do not assess the adverse effect on hiring. Overall, we believe that our results add to the micro evidence on the two effects of adjustment costs on hiring and layoff, especially by providing unusually clear evidence on the effect on hiring, thanks to a unique natural experiment.

The paper proceeds as follows. Section 2 details the legislation of the Delalande tax and interprets its changes in terms of natural experiments. Section 3 presents the empirical strategy and the data. Section 4 deals with the effect on hiring, and section 5 with the effect on layoffs. Section 6 concludes.

\section{Overview of the Delalande tax: legislative changes and natural experiments}

Since its introduction in 1987, the Delalande tax has been modified several times. However, its principle is remained unchanged. Firms laying off workers above a certain age threshold (55, and 50 later on) have to pay a tax ("la contribution Delalande") to the UI system (UNEDIC). This tax is proportional to the gross wages of the worker. It is only due if the worker is employed under an indefinite term contract (CDI). Only the private sector is concerned (civil servants may not be laid off). Starting in 1992, the tax depends on the age of the laid off worker and, for some periods, on the size of the firm (table 1). Exemption rules also vary. These changes are sources of variation that help identify the effects of the tax. However, they are not exogenous and may be contemporaneous of other major changes affecting the employment prospects of older workers. This section therefore reviews the main changes in details to assess how close we are from "pure" natural experiments.

\section{The introduction of the tax (1987)}

As France does not have an experience rating system for employment protection, introducing the Delalande tax may appear as a major change. It is therefore interesting to

dismissals (in French, “licenciement”). 
notice that this change occurred almost by surprise: it was voted as an amendment to a law on long-term unemployment, and the government does not seem to have been involved in its elaboration - a member of Parliament, Delalande, proposed the amendment during the night when the vote took place. For sure, this is not sufficient to ensure that the introduction of the tax can be considered as exogenous, thus providing a pure natural experiment. The amendment had two purposes: restoring the financial balance of the UI system and fighting against a recent and sharp increase in the number of layoffs of older workers. This increase was explained by a weakening of employment protection in 1986, with the suppression of the administrative authorization that used to be required for layoffs. The government used this administrative authorization as a way to induce firms to use early retirement schemes for early exits of older workers, for which they had to pay part of the cost. After 1986, firms rapidly turned to layoffs and unemployment, that were less costly to them and still provided generous unemployment benefits to the older workers. Hence, for some part at least, the introduction of the Delalande tax is driven by a general change in the strictness of employment protection. As this change concerned all workers and was not due to changes in the employability of older workers around 1987, it is exogenous with regard to the relative demand for older workers and can thus be considered as a good source of variation to study the impact of adjustment costs on that relative labor demand. One caveat applies, though: the surge in layoffs of older workers that preceded the introduction of the tax may have consequences on the relative evolution of layoff rates of older workers, compared with younger ones. Specifically, this surge may partly reveal an increasing trend in layoff rates of older workers; if that trend is neglected, the restriction in layoffs due to the Delalande tax may be underestimated. Conversely, if the surge in layoffs before 1987 was strictly accidental, perhaps only the most productive older workers remained in employment in 1987, thus leading to lower layoff rates after 1987: if this is not taken into account, the estimated effect of the Delalande tax would be biased upward.

To summarize, the introduction of the Delalande tax in 1987 presents some of the features of a natural experiment. It is driven by an economy-wide shock (a global change in employment protection) that is not directly related to the outcome of interest (the employment of older workers). However, two issues arise: trends in the relative demand for older workers as well as changes in the unobserved heterogeneity may bias inference based on a comparison of the evolution of layoff rates across ages. As we will see, these are recurring problems for which tentative solutions are presented in the next section. However, we first continue our overview of legislative changes, hoping to find more clear cut natural experiments first. 


\section{The 1992 changes}

Two major changes occur in 1992. First, the schedule of the tax is modified. Workers above 50 (instead of 55) are now liable for the tax, but the amount due in case of layoffs varies with age, from one to six months of gross wages. Overall, this is a substantial increase: the amount of the tax is multiplied by two for workers above 56. Figure 1 compares the cost of the Delalande tax to the mandatory severance payments that are also due (to the worker and not to the UI system) in case of layoff. ${ }^{2}$ After the age of 55, the amount of the Delalande tax is now clearly larger than the average of mandatory severance payments. Second, the tax is now restricted to workers who were hired before the age of 50 or who had been unemployed for less than three months if they were hired after the age of 50 .

The increase in the tax schedule in 1992 constitutes a complex source of variation. The political context has changed: the government decides this increase as part of an effort to increase the employment rate of older workers ${ }^{3}$ and of a global move toward more stringent employment protection, reversing changes operated by the 1986-1988 government. Second, the economic context is characterized by a slowdown of growth that announces France's most severe depression since World War II, in 1993. This particular context may have had consequences on the relative demand for older workers. Third, the variation in the tax schedule with age renders the incentives more complex. On one hand, a higher tax level at a given age makes it more costly to lay the worker off. But, on the other hand, the fact that the tax increases with age gives incentives to anticipate the layoff, so as to avoid to be liable for a higher layoff cost in the future. Intuitively, the effect of the 1992 schedule can therefore be decomposed in two parts: the higher the level of the tax, the lower the layoff rates; but the higher the slope of the tax, the higher the layoff rates. ${ }^{4}$ This second effect - the effect of the slope of the schedule - also existed for workers just below 55 in the 1987 schedule: it is now smoothened and applies to protected workers as well as to workers entering the protected age. The consequence for empirical analysis is that we cannot think of the change in 1992 as creating two groups - a control group of unprotected workers, a treatment group of protected workers - as in a typical natural experiment framework; but rather as creating a continuum of more or less protected workers, depending on the level and the slope of the tax schedule at each age.

\footnotetext{
${ }^{2}$ In France, mandatory severance payments depend on the tenure of the worker in his firm. This is taken into account in the computations of figure 1: we use the distribution of workers' tenure to compute the average amount of severance payments. However, additional severance payments may be due depending on the industry; these are not taken into account here. For details on the cost of employment protection in France, see Abowd and Kramarz (2003).

${ }^{3}$ Access to early-retirement schemes is slightly restricted on the same period.

4 This decomposition can be derived in a formal model of labor demand with adjustment costs (see Behaghel, Crépon and Sédillot, 2005). A key assumption is that there is no uncertainty, so that the schedule of the tax years ahead does not intervene.
} 
The second change - the exemption of the tax for workers who were older than 50 and had been unemployed for at least three months at the time of hiring - provides a unique setting to study the effect of employment protection on hiring. Indeed, it introduces a discontinuity, at the age of 50, between unemployed workers for whom the firm could be liable of the tax, if it hires them before the age of 50 and then fires them after they are 50, and unemployed workers to whom the tax will not apply, as they are above 50. Such discontinuities are particularly helpful for evaluation: the effect of the tax on hiring can be estimated from differences in hiring rates above and below the 50-year threshold. To get a sense of the advantage of the natural experiment it provides, it is helpful to compare it to the introduction of the tax in 1987. When the tax was introduced, the consequence was that all unemployed workers became more costly to hire, as the firm was facing the possibility to pay the Delalande tax if it were to lay the worker off after the age of 55. Only the degree to which the firm was likely to incur that cost varied according to the age of hiring (once discounted, the Delalande cost was probably negligible for workers hired below the age of 30, for instance). However, disentangling this (continuous) effect of age on the expected Delalande cost from the (continuous) impact of age on productive characteristics that determine hiring rates would be problematic. After 1992, a comparison of hiring rates just above and below the age of 50 is in principle enough to identify the effect of the tax on hiring, under the assumption that other age effects on hiring rates are continuous and thus negligible on very short age windows. In other words, we are very close to the pure natural experiment: unemployed workers are split into two groups according to a criterion that is almost as good as random, i.e. being just above or below 50. The first group (below 50) is "treated" (liable for the tax) and the other (above 50) is not, thus providing the counterfactual.

\section{The 1998 change}

In 1998, the major change is an increase in the schedule of the tax for firms with more than 50 workers. This rise in the tax is decided in a context of rapidly growing employment that benefits all categories of workers, except older unemployed workers. But a key feature of the change is that it only concerns firms with more than 50 workers: it thus introduces a second discontinuity that is particularly favorable for the analysis. Specifically, we are now able to compare workers of the same age group at the same date, but in firms of different sizes: no assumption is therefore required on the stability of the relative labor demand across ages, contrarily to analyses of the changes in 1987 and 1992. The only assumption is that this relative labor demand has similar evolutions in large and small firms. A second problem - unobserved heterogeneity - is also mitigated, as firms with more or less than 50 workers were under the same Delalande schedule before 1998 and were likely to be equally selective. Overall, this change appears as the most promising one to study the effect of the tax on layoffs. 
Having reviewed the various changes in the employment legislation, we now turn to a more formal presentation of our empirical strategy.

\section{Empirical strategy}

The various changes in the Delalande tax schedule provide natural experiment settings to study its impact by comparing the probability of layoff and hiring of different groups of workers at specific periods of time. However, the most convincing natural experiments to study the impact on layoffs are not as convincing to study the impact on hiring, and vice versa. We therefore choose to closely follow the natural experiments available by separately estimating these two effects, at the expense of providing a global assessment of the impact of the tax on employment. In what follows, we present the specifications used to study successively the effect on hiring and the effect on layoff, before reviewing briefly the data we use.

\section{The effect on hiring}

The identification of the indirect effect uses the discontinuity, created in 1992, between unemployed workers affected or not by the tax, depending on whether they are above or below 50. Formally, the effect of the tax is defined as:

$$
\Delta(\varepsilon)_{\text {post }}=(\mathrm{E}(\mathrm{h}(\mathrm{t}, 50-\varepsilon))-\mathrm{E}(\mathrm{h}(\mathrm{t}, 50+\varepsilon)))_{t \geq 1992},
$$

where $\mathrm{h}$ is a binary variable that denotes the occurrence of a hiring at date $\mathrm{t}$, for a worker aged just below (or just above) 50, with $\varepsilon$ being as close as possible to 0 . There is however a tradeoff between the comparability of the two groups and the precision of the estimates. Increasing the age window around 50 makes the two groups more heterogeneous, but it increases the sample size and makes the estimates more precise. Our approach is therefore to present results for windows of 1,3 and 5 years above and below the age of 50 . As the two groups now risk to differ, we rather consider a difference-in-difference specification, where the effect on layoff is defined as:

$$
\begin{aligned}
\Delta(\varepsilon) & =\left[\left.(\mathrm{E}(\mathrm{h}(\mathrm{t}, 50-\varepsilon))-\mathrm{E}(\mathrm{h}(\mathrm{t}, 50+\varepsilon)))\right|_{t \geq 1992}\right]-\left[\left.(\mathrm{E}(\mathrm{h}(\mathrm{t}, 50-\varepsilon))-\mathrm{E}(\mathrm{h}(\mathrm{t}, 50+\varepsilon)))\right|_{t<1992}\right] \\
& =\left.\Delta(\varepsilon)\right|_{\text {post }}-\left.\Delta(\varepsilon)\right|_{\text {pre }} .
\end{aligned}
$$

This parameter can be equivalently defined by:

$$
\mathrm{E}(\mathrm{h} \mid 1(\mathrm{t} \geq 1992), 1(\mathrm{a}<50))=\alpha_{0}+\alpha_{\text {post }} 1(\mathrm{t} \geq 1992)+\alpha_{\text {below } 50} 1(\mathrm{a}<50)+\Delta(\varepsilon) 1((\mathrm{t} \geq 1992) \&(\mathrm{a}<50)),
$$

where a denotes age and 1(.) denotes the dummy function. Furthermore, the composition of the groups of workers aged below and above the 50-year threshold may evolve in time; we introduce a set of variables $\mathrm{x}$ to control for observable changes. This defines the parameter $\Delta^{\mathrm{c}}(\varepsilon)$ to be estimated, net of composition changes in the two compared groups: 
$\mathrm{E}(\mathrm{h} \mid \mathrm{x}, 1(\mathrm{t} \geq 1992), 1(\mathrm{a}<50))=\mathrm{xb}+\alpha_{\text {post }} 1(\mathrm{t} \geq 1992)+\alpha_{\text {below50 }} 1(\mathrm{a}<50)+\Delta^{\mathrm{c}}(\varepsilon) 1((\mathrm{t} \geq 1992) \&(\mathrm{a}<50))$

\section{The effect on layoff}

The fundamental difficulty to identify the effect of the Delalande tax from time-series variation is the strong counter-cyclicality of layoffs, as illustrated in figure $2 .{ }^{5}$ Time-series correlations between the tax rate and layoffs cannot be interpreted if one does not control for other sources of changes in layoff rates, including the business cycle. We proceed in two steps, with two complementary strategies. The first one uses all changes in the tax schedule, with workers below the age of 50 being used as a control group. The second one is closer to the "regression discontinuity" approach used for the direct effect: again, it builds on a particular legislation change that occurred in 1998 and created a discontinuity between firms with more and less than 50 employees.

Using the three legislative changes (1987, 1992 and 1998)

As described above, three changes in the tax schedule offer room for identification of the effects of the tax. However, inference must account for other simultaneous changes. A natural idea to control for cycles and possible trends in layoffs is to use younger workers, unaffected by the tax, as a control group. We first pursue this strategy, estimating the following model:

$$
E(s \mid a, x, t)=x b+\sum_{t_{0}=1983}^{2001} \lambda_{t_{0}} 1\left(t=t_{0}\right)+\sum_{a=40}^{58} \alpha_{a} 1\left(a_{i t}=a\right)+\gamma c_{t}(a)+\delta \Delta c_{t}(a),
$$

where $\mathrm{s}$ is a dummy variable for layoff, $\mathrm{x}$ are control variables, $c_{t}(a)$ and $\Delta c_{t}(a)$ are the level and the slope of the tax at age a. Parameters $\lambda_{t}$ and $\alpha_{a}$ capture the respective effect of the business cycle and of age profile on the probability of a layoff. The age profile of layoffs is assumed to be stable across periods. This is the key assumption of stable relative labor demand across ages, which appears as the cost to pay in order to use all the different changes in the tax schedule for identification.

As discussed in the previous section, when the profile of the tax is not flat with age, the direct effect has two components, which are captured by parameters $\gamma$ (expected to be negative) and $\delta$ (expected to be positive). An additional underlying assumption is that the effects of the two components of the tax (its level and its slope) on the probability of being laid off are linear.

This first strategy can be criticized for two reasons. First, using younger workers as a control group assumes that the relative demand for labor across ages is acyclical. This does

\footnotetext{
${ }^{5}$ The periods on figure 2 are the periods of the different tax schedules. But 1983-1986 and 1993-1998 are also low phases of the business cycles, whereas the other two periods are characterized by strong activity.
} 
not hold if different ages play different roles in the adjustment of the labor force, as results by Aubert (2003) tend to show. Correlatively, it does not account for possible trends in the relative demand for older workers, which could lead to biases. Assume for example that there is a decreasing trend in the relative demand for older workers, leading to more layoffs. As the tax has an increasing trend, this increase in layoff rates of older workers would be attributed to the tax. Second, this approach does not take into account selectivity effects. Indeed, the tax changes firms' recruiting behavior (through the effect on hiring): firms are likely to become more selective when hiring workers close to the age of 50 . If this selectivity is not observed by the econometrician, it will affect the distribution of unobserved heterogeneity, that will not be stable across periods. This can bias the estimates upward: increased retention would be attributed to the direct effect of the tax, instead of being attributed to the indirect effect (via the higher selectivity of firms). One way to control for this selectivity is to introduce dummies for three hiring periods (1987-91, 199298, 1999-2001). However, this restricts the source of identification.

\section{Focusing on the 1998 reform}

Given these limitations, we supplement this first strategy by a second one, using only the specific change in the tax that occurred in 1998. This change introduced a discontinuity, with firms just below and above the threshold of 50 employees being ex ante similarly, and ex post differently affected by the tax. At a given age a, we can thus estimate the effect $\Delta$ of the increase in the tax schedule by a difference-in-difference approach:

$$
\mathrm{E}(\mathrm{s} \mid \mathrm{x}, t \text {, Size } a)=\mathrm{xb}+\alpha_{\mathrm{post}} 1(\mathrm{t}>1998)+\alpha_{\mathrm{above} 50} 1(\text { Size }>50)+\Delta(\mathrm{a}) 1((\mathrm{t}>1998) \&(\text { Size }>50)),
$$

where Size indicates the size of the firm. Using firms with less than 50 employees as a control group is useful, as it enables us to overcome the objections to the first strategy. First, relative demand for older workers does not need to be acyclical nor without trend, as long as the cyclicality and the trend are common to firms of different sizes. Second, selectivity is less an issue: before 1998, firms with less than 50 workers had exactly the same incentives as larger firms to be selective in their hiring decisions. ${ }^{6}$ For workers aged above $50, \Delta$ (a) can be interpreted as the effect of the Delalande tax under the identifying assumption that the gap between layoff rates in small vs. large firms is stable across time, except for the effects of the Delalande tax. For workers aged more than 50, this identifying assumption cannot be separately tested from the effect of the change in the tax. But for workers aged less than 50, it can. Indeed, we can test whether $\Delta(\mathrm{a})$ with $\mathrm{a}<50$ is significantly different from 0 for workers aged, say, between 40 and 49 . If not, the identifying assumption is not rejected (for this age range). It is therefore plausible that the

\footnotetext{
${ }^{6}$ As far as the Delalande tax is concerned.
} 
assumption also holds for workers aged 56 to 59 , so that for them the estimate of $\Delta$ (a) for a between 56 and 59 can be interpreted as the effect of the tax.

It should be noted that $\Delta(\mathrm{a})$ combines the two effects of the level and the slope of the tax, that we previously distinguished. The estimates might seem less easy to interpret, as they are generally the sum of a negative and a positive effect. But this is not the case for workers aged 56 to 59: as can be noted from table 1, the level of the tax increased for them after 1998 and the slope decreased. The expected impact is unambiguously a decrease in layoff rates.

\section{The data}

We use the 1983 to 2001 issues of the French Labor Survey (Enquête Emploi). This is a rotating panel, with yearly interviews: members of a household are interviewed three years in a row, and then leave the panel. Detailed questions on the employment status at each interview make it possible to identify two transitions per worker. We use each transition as an observation. ${ }^{?}$

The advantage of using the Enquête Emploi is that it provides a host of individual characteristics that impact on hiring and layoff. Information on the firm (firm size, industry) is also available. Particular attention is paid to the definition of the employment status. Indeed, only workers under indefinite duration contracts in the private sector are liable for the tax. Due to a change in the design of the Enquête Emploi, this status has to be inferred from different questions (see Behaghel et al., 2005).

\section{The effect on hiring}

Figures 3 and 4 show the yearly rate of transition from unemployment to employment under indefinite duration contract, for workers aged below and above 50, for four subperiods corresponding to the changes in the tax. The first two periods take place before the 1992 change, the last two after. Transition rates are given for the different age windows and separately for men and women. On the right, they are given net of compositional changes over the whole period. Specifically, we control for changes in composition along the following dimensions, using a linear probability model: unemployment duration, industry and occupation in previous job, education level, rural or urban place of residence, family situation.

\footnotetext{
7 To account for the fact that the same individual can be observed twice so that error terms can be autocorrelated, we compute robust standard errors allowing for individual clusters.
} 
Relative changes go in the expected direction for men. For instance, on the 44 to 55 age window, men aged more than 50 had lower chances to become employed than their younger counterparts, before the 1992 change. This gap narrows down after 1992. The relative evolution of the transition rates is thus consistent with the prediction of an adverse indirect effect of the tax on unemployed workers below 50. The fact that the two groups had different transition rates before 1992 may seem contradictory with the regression discontinuity design, that would have no difference before the introduction of the discontinuity. But this difference is sizeable only for the larger windows and does not appear systematically when the age groups are very close (for the 48-51 window), as expected. Hence, the initial difference mostly confirms the need to further control for observed heterogeneity when the age window widens.

This is what difference-in-difference estimates do, as presented in tables $\mathbf{2}$ and $\mathbf{3}$. The visual impression from the graphics is confirmed. Results for the narrowest window are not precise enough to be interpreted. For the medium and large window, the difference-indifference is statistically different from 0 for men, in the expected direction, and quite sizeable: about one third of the initial transition rates. For men, the prediction of an indirect effect of the tax is thus confirmed. This effect does not appear for women. One reason may be that transition rates are lower, making changes less detectable. Another conjecture is that the transitions of unemployed women toward employment are also driven by labor supply determinants that make it more difficult to identify labor demand effect such as those of the Delalande tax.

\section{Decomposing the relative effect}

The difference-in-difference estimates of table 2 and 3 only give a relative effect of the tax. In other words, they enable us to test the existence of an effect of the tax on hiring, but not to gauge its size. Indeed, as the schedule of the tax is modified at the same time, the estimates are made of two parts: an improvement of the situation of the unemployed above 50 and a deterioration of the situation of those below 50. To assess by how much the probability to recover a job has increased (respectively decreased) for the unemployed aged above 50 (respectively below 50), we need to take as a reference a group whose situation has not changed. The choice of the control group depends on a tradeoff: the younger the age group we consider, the lower the risk that the control group is affected by the changes in the Delalande tax (indeed, once discounted, the risk that very young workers be laid off and liable for the tax becomes negligible). At the same time, the wider the age gap between the control and the treatment groups, the less relevant the comparison. In table 4, we therefore compute changes in hiring rate (before and after 1992) for various possible control groups: workers aged 30-35, 35-40 and 40-45. It turns out that they have very different changes in hiring rates. If we choose the 40-45 year old group as a reference, 
the relative decline in hiring rates of unemployed workers aged $46-48$ vs. $50-52$, which is $6.1 \%$, can be decomposed in a decrease by $2.1 \%$ for workers aged 46 to 48 and an increase by $4.1 \%$ for workers aged $50-52 .{ }^{8}$ In other words, the Delalande tax is estimated to have reduced the probability that workers aged 50 to 52 between 1987 and 1992 could find a job by 4.1 percentage points (about $25 \%$ of the initial transition probability).

\section{Temporal analysis}

Ideally, the difference-in-difference analysis should be done on a very short period before and after the change, in order to avoid other changes that may affect the results. Very short periods (e.g. one-year) cannot be used here, as the sample of unemployed workers would be too small to precisely estimate transition rates. Until now, we have therefore used a very long time period, from 1983 to 2001. Besides providing sufficient samples of unemployed workers, this long period has the advantage of covering two business cycles, one before and the other after the reform. If the business cycle has some effects on the relative demand for workers just below and just above 50, these effects should cancel out on the period. However, it is important to check whether the changes we observe are robust to the choice of other periods. Table 5 displays such an analysis for men, using the medium age window (46-53). Each cell gives the difference-in-difference estimate that corresponds to the relative evolution of hiring rates of unemployed workers below 50 compared to unemployed workers above 50. Columns 1 and 2 consider two different periods before 1992: the original one (1983-1991) and a shorter one (1987-1991). The different lines systematically review periods of 1 year, 2 years, 3 years, etc. after 1992. The largest "before" and "after" periods correspond to table 3, yielding the same difference-indifference estimate $(-6.3 \%)$.

Looking first at the different lines of column 1, we find that the difference-in-difference effect appears just after 1992, even though it is imprecisely estimated at first as samples are too small when including only a few years after the reform. Second, comparing the results of columns 1 and 2, it appears that they are robust to the choice of the "pre-reform" period. Overall, this temporal analysis reveals that, though small samples are an issue, the results do not seem very sensitive to the period chosen for the estimation.

\footnotetext{
${ }^{8}$ Age is given at the beginning of the year of observation. Workers aged 49 (at the beginning of the yer) are not included as they may be 49 or 50 at the date of the transition. See below the monthly calendar that makes if possible to include all workers by precisely measuring the age at the transition date.
} 


\section{Robustness checks}

We performed a variety of robustness checks. First, results are qualitatively unaffected by the use of other functional forms to model the transition rates (logit or probit; results not reported here).

Second, a particularity of the Delalande tax is that it only concerns workers hired under indefinite term contracts. Therefore, no significant difference-in-difference effects should appear for workers hired under fixed-term contracts. This is checked by table 6 for men. If anything, the probability of finding a job under fixed-term contracts has increased for men below 50 compared to men above 50 . A tentative explanation could be that firms hiring workers below 50 have tended to switch to fixed-term contracts, as these contracts are not liable for the Delalande tax. Nonetheless, this evolution is not statistically significant. A more conservative interpretation of the table is therefore that our identification strategy is not invalidated: there is something specific in the relative decrease in the chances of workers below 50 to be hired under indefinite duration contracts. As these contracts are those concerned by the Delalande tax, this leaves the 1992 change in the tax as a likely explanation.

Third, the exemption from the Delalande tax only applies to workers older than 50 who have spent more than three months unemployed. We cannot check whether hiring occurred after more or less than three months of unemployment when we use yearly transition rates. Starting in 1989, a monthly calendar of activity is available and makes it possible to measure the employment status of the worker, month by month. A further advantage of that calendar is that there is no ambiguity on the age of the worker at the time of the transition (whereas it was measured only at a yearly precision above). The drawback is that the "pre-reform" period is shorter: 1989 to 1991, reducing the precision of estimates. Table 7 gives results similar to table 3 but based on the monthly calendar. Once taken into account the fact that monthly and not yearly estimates are reported, the results are quite similar to previous ones. They are however statistically less significant, due to the smaller sample size and perhaps to reporting errors (the monthly calendar is taken from retrospective information at the yearly survey date).

Fourth, employment policies were quite active during the period considered, and they were sometimes differentiated across age groups. In particular, subsidies to hiring were introduced in 1989-1990 for the long-term unemployed. They were particularly generous for workers above 50. They were modified several times, depending on the time the worker had spent unemployed, her age and other individual characteristics (disability,...). It is therefore possible to introduce additional dummies for three levels of subsidies across the period (no subsidy before 1989 and for the short-term unemployed afterwards; small 
subsidies for the long-term unemployed after 1990; large subsidies for specific groups after 1990, with changes in 1995). Table 8 displays the results. Paradoxically, the subsidies do not seem to have any significant effect on hiring probabilities; if anything, the point estimates indicate negative effects. The difference-in-difference effect attributed to the Delalande tax increases compared to table 3. Overall, this table confirms the interpretation that the larger hiring rates of unemployed aged above 50 is due to the exemption from the Delalande tax after 1992.

\section{The effect on layoff}

\section{Using the three legislative changes $(1987,1992$ and 1998)}

The main results are given in table 9. We regress a dummy variable for layoff on characteristics of the Delalande tax schedule at different periods (linear probability model). The six columns differ by the list of variables included. In column 1, besides the level and the slope ${ }^{9}$ of the Delalande tax, we introduce only age and period dummies. Column 2 and 3 add controls for individual characteristics: tenure and education (column 2), skill group, location and size of the plant, wage (column 3). Column 4 introduces only the level of the tax (and not the slope). Column 5 interacts age dummies with two period dummies (before and after 1998); this can be identified separately from the effects of the change in the Delalande tax as that change only concerned large firms. Column 6 introduces dummy variables for the period during which the worker was hired (using the different periods of the Delalande schedule): the idea is that workers hired under the most stringent schedule are more highly selected and have a lower probability of being laid off.

Overall, for men, the level and the slope of the tax schedule have the expected effect: a higher level of the tax deters firms from laying older workers off, whereas a higher slope tends to accelerate layoffs. However, the effect of the slope is not statistically significant. Comparing the various columns, it appears that controlling for individual characteristics of the workers matters. Estimates are reduced when controlling for tenure and education, in particular, and they are further reduced once introducing dummies for the various hiring periods (column 6). However, this last regression relies on a limited source of variation, as age, tenure and the hiring period are highly correlated. These last estimates should thus be taken with care. In column 4, we check that the impact of the level of the tax is robust to

\footnotetext{
${ }^{9}$ The slope of the tax is defined as the variation in the tax level from age 1 to age a+1. Level and slope of the tax are computed from the tax schedule in table 1.
} 
the presence or not of the slope of the tax schedule. Allowing for a change in the impact of age on layoff probability in 1999 (column 5) does not dramatically alter the results.

In the same way as for hiring, results for women are not significant. This is less easily interpreted in terms of labor supply, as older women who have a job at the age of 50 are quite attached to the labor force. A second puzzle is that results are quite sensitive to the specification: the impact of the Delalande schedule is no longer significant if we use a probit or logit model.

To get an idea of the order of magnitude implied by the estimates of the linear probability model, figure 5 displays the predicted layoff rates with and without the tax, based on point estimates for men in column 3. The predicted impact is sizeable only for the last period in large firms.

\section{Using the 1998 change only}

Tables 10 and 11 display the results of the difference-in-difference approach based on the 1998 change, for men and women. In 1998, the Delalande tax was doubled for large firms (more than 50 employees) only. We restrict the time window to the years 1997-1998 (before) and 1999-2000 (after), as those were all years of economic boom in France. In panel B (on the right), we compare (control) firms with 20 to 49 employees to (treatment) firms with 50 to 99 employees - the closest we can get around the discontinuity at 50. In panel A (on the left), we include all firms with more than 50 employees in the treatment group - thus better covering the population affected by the change, but making the control group probably less appropriate.

On workers aged 40 to 49, we can test the identifying assumption that the labor demands of small and large firms evolved similarly. For men and women alike, layoff rates are lower in firms with more than 50 employees (panel A). However, this difference does not change significantly between 1997-98 and 1999-2000. Therefore, we cannot reject our identifying assumption that relative labor demand did not change for other reasons than the change in the Delalande tax.

For workers aged 50 to 55, the consequences of the 1998 change are theoretically indeterminate: the level of the tax schedule increased, but so did its slope, potentially leading to an acceleration of layoffs. For men, relative layoff rates tended to increase in large firms (compared to small firms): the point estimate is .9 percentage point (panel A) or .8 percentage point (panel $\mathrm{B}$ ), but it is not statistically significant. Conversely, the estimate is negative in both panels for women, and it is not significant either. 
The estimates for workers aged 56 to 58 are easier to interpret, as the theory predicts a relative decrease in layoff rates in larger firms. Point estimates are consistent with this prediction for men (-.2 and -1.7 percentage points in panel A and B, respectively), but they are very imprecise and not statistically significant. The same imprecision appears for women; the point estimate has the negative expected sign only in panel B (-2.3). For this particular age group, employment rates are low and sample sizes are small: it may explain part of the imprecision. But it remains true that layoffs are not well predicted by the model, probably reflecting the important role of idiosyncratic shocks.

It is interesting to check whether these results, though imprecise, are consistent with those obtained using the three legislative changes (table 9 and figure 5). As shown on figure 5 (two bottom graphs), the latter approach predicts a reduction in layoff rates by about 1 percentage point in large firms, after 1998, for workers aged 56 to 58. This is in between the point estimates obtained for men in panel A and B. Conversely, the very small effect predicted for women in table 9 is not consistent with the sizeable decrease predicted in table 10, panel B. However, in all cases, confidence intervals are wide, and the results do not differ statistically. Overall, though the two methods to study the effect on layoff are consistent, not of them yields clear cut evidence on the labor hoarding effect.

\section{Discussion}

Our results add micro evidence on the effects of employment protection - with experience rating features - on labor flows. The most striking result is the negative effect of the tax on the hiring probability of unemployed workers from or close to the protected age group. The evidence comes from the natural evidence provided by the introduction of a new rule in 1992, exempting some of the workers previously protected. It is robust to various checks (variation in the age and time windows, in the frequency of observation - monthly or yearly, control for specific employment policies,...). This strong adverse affect is a key learning to take into account when applying experience rating; if experience rating is targeted upon a category of workers with a strong unemployment risk, hiring discrimination against these workers is a real issue.

Paradoxically, the effect on layoffs, which are in theory more direct, are harder to uncover. This contrasts with other studies, in particular in Finland, where Hakola and Uusitalo (2005) find a robust effect of experience rating on the layoff of older workers. Part of the explanation may be technical, as Hakola and Uusitalo take advantage of a legislative change that is particularly favorable for evaluation. The order of magnitude of their effects is not larger than our point estimates, though: in Finland, an increase in the layoff cost by one year of wages yields a decrease in the layoff probability by about 1 point of percentage. The confidence intervals we obtain for France are consistent with that order of 
magnitude; but they are too wide to be conclusive. The imprecision of our estimates may be due to less clear favorable sources of variation (when studying the three legislative changes of 1987, 1992 and 1998) and to smaller sample size (when studying the natural experiment of the 1998 reform on workers aged 56-58). However, it is also possible that the behavior of labor demand differs in France, and that the impact of financial incentives is reduced by other factors (as a strong social pressure for early exits, whatever its cost).

To understand these results further, as well as to be able to provide a global evaluation of the measure, a complementary analysis is to estimate a structural model of the labor demand for different age groups. This is a promising venue for further research. 


\section{References}

Abowd J. et Kramarz F. (2003), « The costs of hiring and separation », Labour Economics, vol. 10, n 5, pp. 499-230.

Acemoglu D. and J. Angrist (2001). Consequences of Employment Protection? The Case of the American with Disabilities Act. Journal of Political Economy, 109(5).

Anderson P et Meyer B. (1997), « Unemployment Insurance, Take-up Rates and the After Tax Value of Benefits », Quarterly Journal of Economics, vol. 112, n³ 3, pp. 913-937.

Anderson P. et B. Meyer B. (2000), « The Effects of the Unemployment Insurance Payroll Tax on Wages, Employment, Claims and Denials », Journal of Public Economics, vol. 78, $n^{\circ}$ 1-2, pp. 81-106.

Aubert P. (2003), "Les quinquagénaires dans l'emploi salarié privé », Économie et Statistique, $\mathrm{n}^{\circ}$ 368, dossier Les travailleurs âgés face à l'emploi, pp. 65-94.

Autor D., J. Donohue and S. Schwab (2002), The Costs of Wrongful Discharge Laws, NBER Working Paper 9245.

Behaghel L., B. Crépon and B. Sédillot (2004), Contribution Delalande et flux sur le marché du travail, Économie et Statistique, n 372, pp. 61-88.

Behaghel L. and J. Gautié (2005), From Internal to Transitional Labour Markets? Firms Restructuring and Early Retirement in France. Mimeo Centre d'études de l'emploi.

Blanchard O. et Tirole J. (2003), « Protection de l'emploi et procédures de licenciement » Rapport du CAE

Cahuc P. et Malherbet F. (2004), «Unemployment Compensation Finance and Labor Market Rigidity », Journal of Public Economics, vol. 88, n³-4, pp. 481-501.

Hakola T. and R. Uusitalo (2005), Not So Voluntary Retirement Decisions? Evidence from a Pension Reform, mimeo presented at the Second EALE-SOLE World Conference, San Francisco, June 2005.

Kugler A. (2004), The Effect of Job Security Regulations on the Labor Market Flexibility: Evidence from the Colombian Labor Market Reform, NBER Working Paper 10125

Pissarides C. (2002), Consumption and Savings with Unemployment Risk: Implications for Optimal Employment Contracts. Mimeo LSE.

Topel R. (1983). On Layoffs and Unemployment Insurance, American Economic Review, 73(4), 541-559.

Topel R. (1984). Experience Rating of Unemployment Insurance and the Incidence of Unemployment, Journal of Law and Economics, 27(April), 61-90. 
Table 1 : Delalande tax schedule according to the age of the laid off worker (monthly gross wages)

\begin{tabular}{|c|c|c|c|c|c|c|c|c|c|c|}
\hline & & 50 & 51 & 52 & 53 & 54 & 55 & $56-57$ & 58 & 59 \\
\hline $\begin{array}{lll}\text { July } & 1987- & \text { June } \\
1992 & & \\
\end{array}$ & All firm size & & & & & & 3 & 3 & 3 & 3 \\
\hline July 1992- Dec 1998 & All firm size & 1 & 1 & 2 & 2 & 4 & 5 & 6 & 6 & 6 \\
\hline \multirow[t]{2}{*}{ Since January 1999} & $\begin{array}{l}\text { More than } 50 \\
\text { employees }\end{array}$ & 2 & 3 & 5 & 6 & 8 & 10 & 12 & 10 & 8 \\
\hline & $\begin{array}{l}\text { Less than } 50 \\
\text { employees }\end{array}$ & 1 & 1 & 2 & 2 & 4 & 5 & 6 & 6 & 6 \\
\hline
\end{tabular}

Source: Legislative texts.

Note : For each age group, the table displays the tax due by the firm to the unemployment insurance system if it lays a worker off. The tax is a function of previous wages, and is stated in months of gross wages.

N.B. For a short period (July 1992 to December 1992), the tax was divided by two for firms with fewer than 20 employees. This is omitted in the table for the sake of simplicity. 


\section{Table 2: Transition rates from unemployment to employment under indefinite duration contracts (men)}

\begin{tabular}{|c|c|c|c|c|c|c|}
\hline & \multicolumn{3}{|c|}{ Without contols } & \multicolumn{3}{|c|}{ With controls } \\
\hline & $\begin{array}{l}\text { 48-51 year } \\
\text { old }\end{array}$ & $\begin{array}{l}\text { 46-53 year } \\
\text { old }\end{array}$ & $\begin{array}{l}\text { 44-55 year } \\
\text { old }\end{array}$ & $\begin{array}{l}\text { 48-51 year } \\
\text { old }\end{array}$ & $\begin{array}{l}\text { 46-53 year } \\
\text { old }\end{array}$ & $\begin{array}{l}\text { 44-55 year } \\
\text { old }\end{array}$ \\
\hline \multirow{2}{*}{$\begin{array}{l}\text { Before 1992, <50 year } \\
\text { old }\end{array}$} & 20,0 & 20,3 & 19,7 & 19,4 & 20,0 & 18,8 \\
\hline & $(2,9)$ & $(1,7)$ & $(1,3)$ & $(2,8)$ & $(1,7)$ & $(1,2)$ \\
\hline \multirow{2}{*}{ After $1992,>50$ year old } & 20,5 & 14,9 & 13,7 & 19,1 & 14,5 & 13,9 \\
\hline & $(2,9)$ & $(1,4)$ & $(1,0)$ & $(2,7)$ & $(1,4)$ & $(1,0)$ \\
\hline \multirow{2}{*}{$\begin{array}{l}\text { Before 1992, <50 year } \\
\text { old }\end{array}$} & 14,3 & 14,6 & 14,9 & 14,6 & 14,7 & 14,8 \\
\hline & $(1,7)$ & $(1,0)$ & $(0,8)$ & $(1,7)$ & $(1,0)$ & $(0,8)$ \\
\hline \multirow{2}{*}{ After $1992,>50$ year old } & 14,6 & 15,2 & 13,0 & 15,3 & 15,5 & 13,4 \\
\hline & $(1,8)$ & $(1,1)$ & $(0,8)$ & $(1,8)$ & $(1,1)$ & $(0,8)$ \\
\hline \multirow{4}{*}{$\begin{array}{l}\text { Before 1992, difference } \\
50-/ 50+ \\
\text { After 1992, différence } \\
50-/ 50+\end{array}$} & $-0,5$ & 5,4 & 6,0 & 0,3 & 5,5 & 4,9 \\
\hline & $(4,1)$ & $(2,2)$ & $(1,6)$ & $(3,9)$ & $(2,1)$ & $(1,6)$ \\
\hline & $-0,3$ & $-0,7$ & 2,0 & $-0,6$ & $-0,8$ & 1,4 \\
\hline & $(2,5)$ & $(1,5)$ & $(1,1)$ & $(2,5)$ & $(1,5)$ & $(1,1)$ \\
\hline \multirow{2}{*}{ Difference-in-difference } & 0,2 & $-6,1$ & $-4,1$ & $-0,9$ & $-6,3$ & $-3,5$ \\
\hline & $(4,7)$ & $(2,7)$ & $(2,0)$ & $(4,6)$ & $(2,6)$ & $(1,9)$ \\
\hline Number of observations & 1211 & 3661 & 6179 & 1211 & 3661 & 6179 \\
\hline
\end{tabular}

Source: Enquête Emploi, 1983-2001

Note : Each column displays the successive steps of a difference-in-difference estimation. The variable of interest is the yearly transition rate from unemployment to employment (under an indefinite term contract). Its mean is computed before and after 1992, among unemployed workers respectively younger and older than 50 (upper part of the table); difference is then taken across age groups (medium part); last, the difference in difference is computed (bottom part). Standard errors (in parenthesis) are robust to autocorrelation of the residuals (individual clusters: individuals can be observed for two transitions). The first three columns display unconditional estimates (simple average transition rates) for various age windows; the last three columns display estimates conditional on a stable structure of observable variables (unemployment duration, industry and occupation in previous job, education level, rural or urban place of residence, family situation; see text). Different age windows are considered (48-51 year old; 46-53 year old; 44-55 year old). 


\section{Table 3: Transition rates from unemployment to employment under indefinite duration contracts (women)}

\begin{tabular}{|c|c|c|c|c|c|c|}
\hline & \multicolumn{3}{|c|}{ Without contols } & \multicolumn{3}{|c|}{ With controls } \\
\hline & $\begin{array}{l}\text { 48-51 year } \\
\text { old }\end{array}$ & $\begin{array}{l}\text { 46-53 year } \\
\text { old }\end{array}$ & $\begin{array}{l}\text { 44-55 year } \\
\text { old }\end{array}$ & $\begin{array}{l}48-51 \text { year } \\
\text { old }\end{array}$ & $\begin{array}{l}\text { 46-53 year } \\
\text { old }\end{array}$ & $\begin{array}{l}\text { 44-55 year } \\
\text { old }\end{array}$ \\
\hline \multirow{2}{*}{$\begin{array}{l}\text { Before 1992, <50 year } \\
\text { old }\end{array}$} & 1313,2 & 1313,3 & 13,6 & 1212,4 & 13,0 & 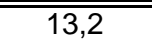 \\
\hline & $(2,3)$ & $(1,3)$ & $(1,0)$ & $(2,3)$ & $(1,3)$ & $(1,0)$ \\
\hline \multirow{2}{*}{ After $1992,>50$ year old } & 11,0 & 9,8 & 9,3 & 10,4 & 9,7 & 9,2 \\
\hline & $(2,2)$ & $(1,2)$ & $(0,9)$ & $(2,2)$ & $(1,2)$ & $(0,9)$ \\
\hline \multirow{2}{*}{$\begin{array}{l}\text { Before 1992, <50 year } \\
\text { old }\end{array}$} & 11,3 & 10,7 & 12,1 & 11,3 & 10,7 & 12,2 \\
\hline & $(1,4)$ & $(0,8)$ & $(0,6)$ & $(1,5)$ & $(0,8)$ & $(0,6)$ \\
\hline \multirow{2}{*}{ After $1992,>50$ year old } & 12,1 & 9,9 & 8,5 & 12,9 & 10,1 & 8,6 \\
\hline & $(1,6)$ & $(0,9)$ & $(0,6)$ & $(1,6)$ & $(0,9)$ & $(0,7)$ \\
\hline \multirow{4}{*}{$\begin{array}{l}\text { Before 1992, difference } \\
50-/ 50+ \\
\text { After 1992, différence } \\
50-/ 50+\end{array}$} & 2,2 & 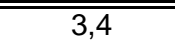 & 4 & 2,1 & 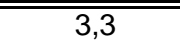 & 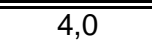 \\
\hline & $(3,1)$ & $(1,7)$ & $(1,3)$ & $(3,2)$ & $(1,7)$ & $(1,3)$ \\
\hline & $-0,8$ & 0,9 & 3,6 & $-1,6$ & 0,7 & 3,5 \\
\hline & $(2,2)$ & $(1,2)$ & $(0,9)$ & $(2,2)$ & $(1,2)$ & $(1,0)$ \\
\hline \multirow{2}{*}{ Difference-in-difference } & "-3,0 & $-2,6$ & -0,7 & -3,7 & $-2,6$ & -0,5 \\
\hline & $(3,8)$ & $(2,1)$ & $(1,6)$ & $(3,8)$ & $(2,1)$ & $(1,6)$ \\
\hline Number of observations & 1337 & 4114 & 7016 & 1337 & 4114 & 7016 \\
\hline
\end{tabular}

Source: Enquête Emploi, 1983-2001

Note : Each column displays the successive steps of a difference-in-difference estimation. The variable of interest is the yearly transition rate from unemployment to employment (under an indefinite term contract). Its mean is computed before and after 1992, among unemployed workers respectively younger and older than 50 (upper part of the table); difference is then taken across age groups (medium part); last, the difference in difference is computed (bottom part). Standard errors (in parenthesis) are robust to autocorrelation of the residuals (individual clusters: individuals can be observed for two transitions). The first three columns display unconditional estimates (simple average transition rates) for various age windows; the last three columns display estimates conditional on a stable structure of observable variables (unemployment duration, industry and occupation in previous job, education level, rural or urban place of residence, family situation; see text). Different age windows are considered (48-51 year old; 46-53 year old; 44-55 year old). 
Table 4: Transition rates from unemployment to employment (men): decomposing the difference-in-difference estimate

\begin{tabular}{lcc|c|cc} 
& $30-35$ ans & $35-40$ ans & $40-45$ ans & $46-48$ ans & $50-52$ ans \\
\hline \hline \multirow{2}{*}{ Before 1992 } & 23,6 & 23,4 & 19,6 & 20,3 & 14,9 \\
& $(1,1)$ & $(1,1)$ & $(1,2)$ & $(1,7)$ & $(1,4)$ \\
\multirow{2}{*}{ After 1992 } & 18,3 & 17,3 & 16,1 & 14,6 & 15,2 \\
& $(0,8)$ & $(0,8)$ & $(0,8)$ & $(1,0)$ & $(1,1)$ \\
\hline \hline \multirow{2}{*}{ Difference after - before } & $-5,3$ & $-6,2$ & $-3,6$ & $-5,7$ & 0,4 \\
& $(1,3)$ & $(1,3)$ & $(1,4)$ & $(1,3)$ & $(1,7)$ \\
\hline \hline Difference-in-difference & $-1,8$ & $-2,6$ & 0,0 & $-2,1$ & 4,0 \\
(reference: 40-45 year & $(1,9)$ & $(2,0)$ & $(0,0)$ & $(2,5)$ & $(2,3)$ \\
\hline \hline Number of observations & 4137 & 3854 & 3328 & 1826 & 1835
\end{tabular}

Source: Enquête Emploi, 1983-2001

Note : Each column displays yearly transition rates from unemployment to employment (under an indefinite term contract), for a given age group. Empirical means are computed before and after 1992 (upper part of the table); difference is then taken between after and before 1992 (medium part); last, the difference in difference is computed, taking the 40 to 45 age group as a reference (bottom part). Standard errors (in parenthesis) are robust to autocorrelation of the residuals (individual clusters: individuals can be observed for two transitions). 
Tableau 5 : Temporal analysis - Men (46-53 year old)

\begin{tabular}{|c|c|c|}
\hline \multirow[b]{2}{*}{ Period after reform } & \multicolumn{2}{|c|}{ Period before reform } \\
\hline & 1983-1991 & 1987-1991 \\
\hline 1992 & $\begin{array}{l}-7.6 \\
(6.7)\end{array}$ & $\begin{array}{l}-7.0 \\
(6.9)\end{array}$ \\
\hline 1992-1993 & $\begin{array}{l}-5.3 \\
(4.3)\end{array}$ & $\begin{array}{l}-4.8 \\
(4.7)\end{array}$ \\
\hline $1992-94$ & $\begin{array}{l}-6.4 \\
(3.6)\end{array}$ & $\begin{array}{l}-5.1 \\
(4.0)\end{array}$ \\
\hline $1992-95$ & $\begin{array}{c}-8.2 \\
(3.2)\end{array}$ & $\begin{array}{l}-6.8 \\
(3.7)\end{array}$ \\
\hline $1992-96$ & $\begin{array}{l}-8.2 \\
(3.0)\end{array}$ & $\begin{array}{l}-6.8 \\
(3.5)\end{array}$ \\
\hline $1992-97$ & $\begin{array}{l}-7.3 \\
(2.8)\end{array}$ & $\begin{array}{l}-6.2 \\
(3.4)\end{array}$ \\
\hline $1992-98$ & $\begin{array}{l}-6.8 \\
(2.7)\end{array}$ & $\begin{array}{l}-5.6 \\
(3.3)\end{array}$ \\
\hline $1992-99$ & $\begin{array}{l}-6.1 \\
(2.6)\end{array}$ & $\begin{array}{l}-4.9 \\
(3.2)\end{array}$ \\
\hline $1992-00$ & $\begin{array}{l}-6.6 \\
(2.6)\end{array}$ & $\begin{array}{l}-5.3 \\
(3.2)\end{array}$ \\
\hline 1992-01 & $\begin{array}{l}-6.3 \\
(2.6)\end{array}$ & $\begin{array}{l}-5.0 \\
(3.1)\end{array}$ \\
\hline
\end{tabular}

Source: Enquête Emploi, 1983-2001

Note: Each cell gives the difference-in-difference estimate that corresponds to the relative evolution of hiring rates of unemployed workers below 50 compared to unemployed workers above 50. Columns 1 and 2 consider to different periods before 1992: the original one (1983-1991) and a shorter one (1987-1991). The different lines systematically review periods of 1 year, 2 years, 3 years, etc. after 1992. Standard errors (in parenthesis) are robust to autocorrelation of the residuals (individual clusters: individuals can be observed for two transitions).

Difference-in-difference estimates are given conditional on a stable composition along observable variables (unemployment duration, industry and occupation in previous job, education level, rural or urban place of residence, family situation; see text). 
Table 6: Transition rates from unemployment to employment under fixed term contracts (men)

\begin{tabular}{|c|c|c|c|c|c|c|}
\hline & \multicolumn{3}{|c|}{ Without contols } & \multicolumn{3}{|c|}{ With controls } \\
\hline & $\begin{array}{l}48-51 \text { year } \\
\text { old }\end{array}$ & $\begin{array}{l}\text { 46-53 year } \\
\text { old }\end{array}$ & $\begin{array}{l}\text { 44-55 year } \\
\text { old }\end{array}$ & $\begin{array}{l}\text { 48-51 year } \\
\text { old }\end{array}$ & $\begin{array}{l}\text { 46-53 year } \\
\text { old }\end{array}$ & $\begin{array}{l}\text { 44-55 year } \\
\text { old }\end{array}$ \\
\hline \multirow{2}{*}{$\begin{array}{l}\text { Before 1992, <50 year } \\
\text { old }\end{array}$} & 6,7 & 6,5 & 7,6 & 26,4 & 5,6 & 6,7 \\
\hline & $(1,8)$ & $(1,0)$ & $(0,9)$ & $(1,8)$ & $(1,0)$ & $(0,8)$ \\
\hline \multirow{2}{*}{ After $1992,>50$ year old } & 6,0 & 5,0 & 4,6 & 5,5 & 4,4 & 4,3 \\
\hline & $(1,7)$ & $(0,8)$ & $(0,6)$ & $(1,8)$ & $(0,9)$ & $(0,6)$ \\
\hline \multirow{2}{*}{$\begin{array}{l}\text { Before } 1992,<50 \text { year } \\
\text { old }\end{array}$} & 8,3 & 8,8 & 9,5 & 8,5 & 9,0 & 9,5 \\
\hline & $(1,4)$ & $(0,8)$ & $(0,6)$ & $(1,4)$ & $(0,8)$ & $(0,6)$ \\
\hline \multirow{2}{*}{ After $1992,>50$ year old } & 5,5 & 6,1 & 5,9 & 5,6 & 6,6 & 6,5 \\
\hline & $(1,1)$ & $(0,7)$ & $(0,6)$ & $(1,2)$ & $(0,7)$ & $(0,6)$ \\
\hline \multirow{4}{*}{$\begin{array}{l}\text { Before 1992, difference } \\
50-/ 50+ \\
\text { After 1992, différence } \\
50-/ 50+\end{array}$} & 0,7 & 1,5 & 3,0 & 0,8 & 1,2 & 2,3 \\
\hline & $(2,5)$ & $(1,3)$ & $(1,0)$ & $(2,5)$ & $(1,3)$ & $(1,1)$ \\
\hline & 2,8 & 2,7 & 3,6 & 3,0 & 2,4 & 3,0 \\
\hline & $(1,8)$ & $(1,1)$ & $(0,8)$ & $(1,9)$ & $(1,1)$ & $(0,8)$ \\
\hline \multirow{2}{*}{ Difference-in-difference } & 2,1 & 1,2 & 0,6 & 2,1 & 1,2 & 0,7 \\
\hline & $(3,0)$ & $(1,7)$ & $(1,3)$ & $(3,0)$ & $(1,7)$ & $(1,3)$ \\
\hline Number of observations & 1211 & 3661 & 6179 & 1211 & 3661 & 6179 \\
\hline
\end{tabular}

Source: Enquête Emploi, 1983-2001

Note : Each column displays the successive steps of a difference-in-difference estimation. The variable of interest is the yearly transition rate from unemployment to employment under a fixed-term contract. Its mean is computed before and after 1992, among unemployed workers respectively younger and older than 50 (upper part of the table); difference is then taken across age groups (medium part); last, the difference in difference is computed (bottom part). Standard errors (in parenthesis) are robust to autocorrelation of the residuals (individual clusters: individuals can be observed for two transitions). The first three columns display unconditional estimates (simple average transition rates) for various age windows; the last three columns display estimates conditional on a stable structure of observable variables (unemployment duration, industry and occupation in previous job, education level, rural or urban place of residence, family situation; see text). Different age windows are considered (48-51 year old; 46-53 year old; 44-55 year old). 


\section{Table 7 : Monthly transition rates from unemployment to employment under indefinite duration contracts (men)}

\begin{tabular}{|c|c|c|c|c|c|c|}
\hline & \multicolumn{3}{|c|}{ Without controls } & \multicolumn{3}{|c|}{ With controls } \\
\hline & $\begin{array}{l}\text { 48-51 year } \\
\text { old }\end{array}$ & $\begin{array}{l}\text { 46-53 year } \\
\text { old }\end{array}$ & $\begin{array}{l}\text { 44-55 year } \\
\text { old }\end{array}$ & $\begin{array}{l}\text { 48-51 year } \\
\text { old }\end{array}$ & $\begin{array}{l}\text { 46-53 year } \\
\text { old }\end{array}$ & $\begin{array}{l}\text { 44-55 year } \\
\text { old }\end{array}$ \\
\hline \multirow{2}{*}{$\begin{array}{l}\text { Before 1992, <50 year } \\
\text { old }\end{array}$} & 2,18 & 2,39 & 2,24 & 2,15 & 2,40 & 2,21 \\
\hline & $(0,53)$ & $(0,31)$ & $(0,23)$ & $(0,53)$ & $(0,31)$ & $(0,23)$ \\
\hline \multirow{2}{*}{ After $1992,>50$ year old } & 2,60 & 1,63 & 1,48 & 2,69 & 1,71 & 1,53 \\
\hline & $(0,53)$ & $(0,23)$ & $(0,17)$ & $(0,52)$ & $(0,23)$ & $(0,17)$ \\
\hline \multirow{2}{*}{$\begin{array}{l}\text { Before 1992, <50 year } \\
\text { old }\end{array}$} & 1,40 & 1,56 & 1,59 & 1,37 & 1,55 & 1,58 \\
\hline & $(0,13)$ & $(0,08)$ & $(0,06)$ & $(0,13)$ & $(0,08)$ & $(0,06)$ \\
\hline \multirow{2}{*}{ After $1992,>50$ year old } & 1,64 & 1,51 & 1,40 & 1,65 & 1,51 & 1,41 \\
\hline & $(0,15)$ & $(0,08)$ & $(0,06)$ & $(0,15)$ & $(0,08)$ & $(0,06)$ \\
\hline \multirow{4}{*}{$\begin{array}{l}\text { Before 1992, difference } \\
50-/ 50+ \\
\text { After 1992, différence } \\
50-/ 50+\end{array}$} & 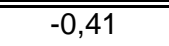 & 0,76 & 0,76 & $-0,54$ & 0,68 & 0,68 \\
\hline & $(0,73)$ & $(0,39)$ & $(0,28)$ & $(0,74)$ & $(0,38)$ & $(0,28)$ \\
\hline & $-0,24$ & 0,05 & 0,19 & $-0,28$ & 0,03 & 0,18 \\
\hline & $(0,19)$ & $(0,12)$ & $(0,09)$ & $(0,19)$ & $(0,12)$ & $(0,09)$ \\
\hline \multirow{2}{*}{ Difference-in-difference } & 0,18 & $-0,71$ & $-0,57$ & 0,26 & $-0,65$ & $-0,50$ \\
\hline & $(0,76)$ & $(0,40)$ & $(0,30)$ & $(0,76)$ & $(0,40)$ & $(0,30)$ \\
\hline Number of observations & 17360 & $\overline{c 52951}$ & 90230 & 1717360 & 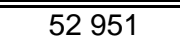 & 90230 \\
\hline
\end{tabular}

Source: Enquête Emploi, 1990-2001 : monthly activity calendar.

Note : Each column displays the successive steps of a difference-in-difference estimation. The variable of interest is the monthly transition rate from unemployment to employment (under an indefinite term contract). Its mean is computed before and after 1992, among unemployed workers respectively younger and older than 50 (upper part of the table); difference is then taken across age groups (medium part); last, the difference in difference is computed (bottom part). Standard errors (in parenthesis) are robust to autocorrelation of the residuals (individual clusters: individuals can be observed for two transitions). The first three columns display unconditional estimates (simple average transition rates) for various age windows; the last three columns display estimates conditional on a stable structure of observable variables (unemployment duration, industry and occupation in previous job, education level, rural or urban place of residence, family situation; see text). Different age windows are considered (48-51 year old; 46-53 year old; 44-55 year old). 
Table 8: Difference-in-difference estimates controlling for hiring subsidies

\begin{tabular}{|c|c|c|c|c|c|c|}
\hline & \multicolumn{3}{|c|}{ Men } & \multicolumn{3}{|c|}{ Women } \\
\hline & $\begin{array}{l}\text { 48-51 year } \\
\text { old }\end{array}$ & $\begin{array}{l}\text { 46-53 year } \\
\text { old }\end{array}$ & $\begin{array}{l}\text { 44-55 year } \\
\text { old }\end{array}$ & $\begin{array}{l}\text { 48-51 year } \\
\text { old }\end{array}$ & $\begin{array}{l}\text { 46-53 year } \\
\text { old }\end{array}$ & $\begin{array}{l}\text { 44-55 year } \\
\text { old }\end{array}$ \\
\hline \multirow[t]{2}{*}{ Delalande } & $-1,5$ & $-7,5$ & $-3,5$ & $-6,5$ & $-2,7$ & $-0,7$ \\
\hline & $(4,8)$ & $(2,9)$ & $(2,2)$ & $(4,3)$ & $(2,4)$ & $(1,7)$ \\
\hline \multirow[t]{2}{*}{ Hiring subsidies (less generous) } & $-4,1$ & $-8,1$ & $-7,0$ & $-1,3$ & $-1,4$ & 0,4 \\
\hline & $(10,9)$ & $(5,6)$ & $(4,4)$ & $(7,8)$ & $(4,8)$ & $(3,7)$ \\
\hline \multirow[t]{2}{*}{ Hiring subsidies (more generous) } & $-5,3$ & $-7,1$ & $-2,9$ & $-3,3$ & $-0,4$ & 1,5 \\
\hline & $(9,9)$ & $(5,2)$ & $(4,1)$ & $(7,2)$ & $(4,5)$ & $(3,5)$ \\
\hline
\end{tabular}

Source: Enquête Emploi, 1983-2001

Note : The first line gives the difference-in-difference estimate that corresponds to the relative evolution of hiring rates of unemployed workers below 50 compared to unemployed workers above 50. Standard errors (in parenthesis) are robust to autocorrelation of the residuals (individual clusters: individuals can be observed for two transitions). The next lines give the estimated impact of hiring subsidies (two dummies corresponding to less and more generous subsidies).

Included controls: unemployment duration, industry and occupation in previous job, education level, rural or urban place of residence, family situation. 
Table 9 : Impact of the Delalande tax on layoff probabilities

\begin{tabular}{|l|c|c|c|c|c|c|}
\hline & $(1)$ & $(2)$ & $(3)$ & $(4)$ & $(5)$ & $(6)$ \\
\hline Men (\# obs.) & 95943 & 95943 & 95943 & 95943 & 95943 & 95943 \\
\hline$c(a)$ & $\begin{array}{c}-0,0037 \\
(0,0005)\end{array}$ & $\begin{array}{c}-0,0019 \\
(0,0005)\end{array}$ & $\begin{array}{c}-0,0013 \\
(0,0005)\end{array}$ & $\begin{array}{c}-0,0013 \\
(0,0005)\end{array}$ & $\begin{array}{c}-0,0017 \\
(0,0006)\end{array}$ & $\begin{array}{c}-0,0008 \\
(0,0005)\end{array}$ \\
\hline$\Delta c(a)$ & 0,0022 & 0,0024 & 0,0021 & & 0,0023 & 0,0019 \\
$(0,0015)$ & $(0,0015)$ & $(0,0015)$ & & $(0,0017)$ & $(0,0015)$ \\
\hline $\begin{array}{l}\text { Women } \\
\text { obs.) }\end{array}$ & 55193 & 55193 & 55193 & 55193 & 55193 & 55193 \\
\hline$c(a)$ & $-0,0013$ & $-0,0002$ & 0,0001 & 0,0002 & 0,0002 & 0,0003 \\
& $(0,0008)$ & $(0,0008)$ & $(0,0079)$ & $(0,0008)$ & $(0,0009)$ & $(0,0008)$ \\
\hline$\Delta c(a)$ & 0,0025 & $\begin{array}{c}0,0027 \\
(0,0024)\end{array}$ & $\begin{array}{c}0,0024 \\
(0,0023)\end{array}$ & & $\begin{array}{c}0,0009 \\
(0,0026)\end{array}$ & $\begin{array}{c}0,0024 \\
(0,0023)\end{array}$ \\
\hline
\end{tabular}

Source: Enquête Emploi, 1983-2001.

Sample: Wage earners from the private sector, aged 40 and above.

Note : Each column displays the regression (linear probability model) of a dummy variable for layoff, separately for men and women. Standard errors (in parenthesis) to autocorrelation of the residuals (individual clusters: individuals can be observed for two transitions). The different columns correspond to different sets of explanatory variables:

(1): dummy variables for age and year; level and slope of the Delalande tax

(2): same as (1) plus a cubic polynomial of tenure and three dummies for education level

(3): same as (2) plus wage (and wage squared), industry (10 categories), occupation (3 categories), plant size

(3 categories), region (7), place of residence (3), mandatory severance payments (level and slope), dummies for tenure below 1 year and below 2 years

(4): same as (3) but with the level of the Delalande tax only

(5): same as (3) but with interaction of the age dummies with two periods: before and after 1998.

(6): same as (3) but with dummy variables for the period of hiring (between 1987 and 1991; less than 50, after 1992; less than 50, after 1999, in large firms only). 
Table 10: Layoff probability by firm size and age group, before and after the 1998 change (men)

\begin{tabular}{|c|c|c|c|c|c|c|}
\hline & \multicolumn{3}{|c|}{ A. All firms with more than 20 employees } & \multicolumn{3}{|c|}{ B. Firms with 20 to 100 employees } \\
\hline & 40-49 year old & $50-55$ year old & $56-58$ year old & 40-49 year old & 50-55 year old & $56-58$ year old \\
\hline Before 1998, firm & 1.6 & 101.3 & 3.2 & 3.0 & 1.1 & 2.9 \\
\hline size $>50$ & $(0.0)$ & $(0.0)$ & $(0.1)$ & $(0.1)$ & $(0.1)$ & $(0.2)$ \\
\hline Before 1998, firm & 3.3 & 3.2 & 3.2 & 2.6 & 1.4 & 3.1 \\
\hline size $<50$ & $(0.0)$ & $(0.1)$ & $(0.1)$ & $(0.1)$ & $(0.1)$ & $(0.2)$ \\
\hline \multirow{2}{*}{ After 1998, firm size $>50$} & 0.9 & 1.4 & 2.2 & 2.6 & 1.7 & 1.2 \\
\hline & $(0.0)$ & $(0.0)$ & $(0.1)$ & $(0.1)$ & $(0.1)$ & $(0.1)$ \\
\hline \multirow{2}{*}{ After 1998 , firm size $<50$} & 2.8 & 2.3 & 2.3 & 1.7 & 1.3 & 3.0 \\
\hline & $(0.0)$ & $(0.0)$ & $(0.1)$ & $(0.0)$ & $(0.1)$ & $(0.2)$ \\
\hline \multirow{4}{*}{$\begin{array}{c}\text { Before } 1998, \text { difference } \\
\text { size } 50+\text { / size } 50- \\
\text { After } 1998, \text { difference } \\
\text { size } 50+\text { / size } 50-\end{array}$} & -1.7 & -1.9 & 0.1 & 0.5 & -0.4 & -0.2 \\
\hline & $(0.0)$ & $(0.1)$ & $(0.1)$ & $(0.1)$ & $(0.1)$ & $(0.3)$ \\
\hline & -1.9 & -0.9 & -0.1 & 0.9 & 0.4 & -1.9 \\
\hline & $(0.0)$ & $(0.1)$ & $(0.1)$ & $(0.1)$ & $(0.1)$ & $(0.2)$ \\
\hline \multirow{2}{*}{$\begin{array}{c}\text { Differences-in- } \\
\text { differences } \\
\end{array}$} & -0.2 & 0.9 & -0.2 & 0.4 & 0.8 & -1.7 \\
\hline & $(0.1)$ & $(0.1)$ & $(0.2)$ & $(0.1)$ & $(0.1)$ & $(0.3)$ \\
\hline Number of observations & 13456 & 6154 & 1147 & 2819 & 1161 & 236 \\
\hline \multirow{2}{*}{$\begin{array}{l}\text { Diffs-in-diffs with } \\
\text { controls }\end{array}$} & -0.1 & 0.9 & -0.3 & 0.7 & 0.6 & -1.7 \\
\hline & $(0.1)$ & $(0.1)$ & $(0.2)$ & $(0.1)$ & $(0.1)$ & $(0.3)$ \\
\hline
\end{tabular}

Source: Enquête Emploi, 1997-2000.

Sample: Male wage earners from the private sector, aged 40 and above.

Note : Each column displays the successive steps of a difference-in-difference estimation. The variable of interest is the yearly layoff probability (from an indefinite term contract). Its mean is computed before and after 1992, for firms with more and less than 50 workers (upper part of the table); difference is then taken across firm size (medium part); last, the difference in difference is computed (bottom part). Standard errors (in parenthesis) are robust to autocorrelation of the residuals (individual clusters: individuals can be observed for two transitions). The first three columns compare firms with 20-49 employees to firms with more than 20 employees; the last three columns compare firms with 20-49 employees to firms with more 50-99 employees. Three age groups are considered: 40-49 year old; 5055 year old and 56-58 year old. The last two lines give the difference in difference controlling for composition effects in: tenure (cubic polynomial), education (3 categories), industry (10 categories), occupation (3 categories), region (7 categories), place of residence (3 categories). 
Table 11: Layoff probability by firm size and age group, before and after the 1998 change (women)

\begin{tabular}{|c|c|c|c|c|c|c|}
\hline & \multicolumn{3}{|c|}{ A. All firms with more than 20 employees } & \multicolumn{3}{|c|}{ B. Firms with 20 to 100 employees } \\
\hline & 40-49 year old & $50-55$ year old & $56-58$ year old & 40-49 year old & 50-55 year old & $56-58$ year old \\
\hline Before 1998, firm & 1,6 & 3,2 & 4,8 & 3,3 & 5,1 & 0,0 \\
\hline size $>50$ & $(0.0)$ & $(0.1)$ & $(0.1)$ & $(0.1)$ & $(0.2)$ & $(0.3)$ \\
\hline Before 1998, firm & 2,9 & 3,1 & 5,4 & 2,3 & 4,1 & 1,7 \\
\hline size $<50$ & $(0.0)$ & $(0.1)$ & $(0.2)$ & $(0.1)$ & $(0.1)$ & $(0.2)$ \\
\hline \multirow{2}{*}{ After 1998 , firm size $>50$} & 1,3 & 2,9 & 5,4 & 2,6 & 2,2 & 2,5 \\
\hline & $(0.0)$ & $(0.1)$ & $(0.2)$ & $(0.1)$ & $(0.1)$ & $(0.3)$ \\
\hline \multirow{2}{*}{ After 1998 , firm size $<50$} & 2,4 & 3,2 & 5,2 & 2,0 & 3,5 & 6,5 \\
\hline & $(0.0)$ & $(0.1)$ & $(0.1)$ & $(0.1)$ & $(0.1)$ & $(0.4)$ \\
\hline Before 1998, difference & $-1,3$ & 0,2 & $-0,5$ & 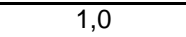 & 1,0 & $-1,7$ \\
\hline size $50+$ / size 50 - & $(0.0)$ & $(0.1)$ & $(0.0)$ & $(0.1)$ & $(0.3)$ & $(0.2)$ \\
\hline \multirow{2}{*}{$\begin{array}{c}\text { After } 1998, \text { difference } \\
\text { size } 50+/ \text { size } 50-\end{array}$} & $-1,1$ & $-0,3$ & 0,2 & 0,5 & $-1,3$ & $-4,0$ \\
\hline & $(0.0)$ & $(0.1)$ & $(0.2)$ & $(0.1)$ & $(0.2)$ & $(0.5)$ \\
\hline \multirow{2}{*}{$\begin{array}{c}\text { Differences-in- } \\
\text { differences }\end{array}$} & 0,2 & $-0,4$ & 0,7 & $-0,5$ & $-2,3$ & $-2,3$ \\
\hline & $(0.1)$ & $(0.1)$ & $(0.3)$ & $(0.2)$ & $(0.3)$ & $(0.5)$ \\
\hline Number of observations & 9088 & 3621 & 802 & 1578 & 651 & 149 \\
\hline Diffs-in-diffs with & 0,1 & $-0,6$ & 0,7 & $-0,4$ & $-2,7$ & $-2,7$ \\
\hline controls & $(0.1)$ & $(0.1)$ & $(0.3)$ & $(0.2)$ & $(0.3)$ & $(0.5)$ \\
\hline
\end{tabular}

Source: Enquête Emploi, 1997-2000.

Sample: Female wage earners from the private sector, aged 40 and above.

Note : Each column displays the successive steps of a difference-in-difference estimation. The variable of interest is the yearly layoff probability (from an indefinite term contract). Its mean is computed before and after 1992, for firms with more and less than 50 workers (upper part of the table); difference is then taken across firm size (medium part); last, the difference in difference is computed (bottom part). Standard errors (in parenthesis) are robust to autocorrelation of the residuals (individual clusters: individuals can be observed for two transitions). The first three columns compare firms with 20-49 employees to firms with more than 20 employees; the last three columns compare firms with 20-49 employees to firms with more 50-99 employees. Three age groups are considered: 40-49 year old; 5055 year old and 56-58 year old. The last two lines give the difference in difference controlling for composition effects in: tenure (cubic polynomial), education (3 categories), industry (10 categories), occupation (3 categories), region (7 categories), place of residence (3 categories). 
Figure 1 : Comparison of the Delalande costs with mandatory severance payments (in monthly gross wages).
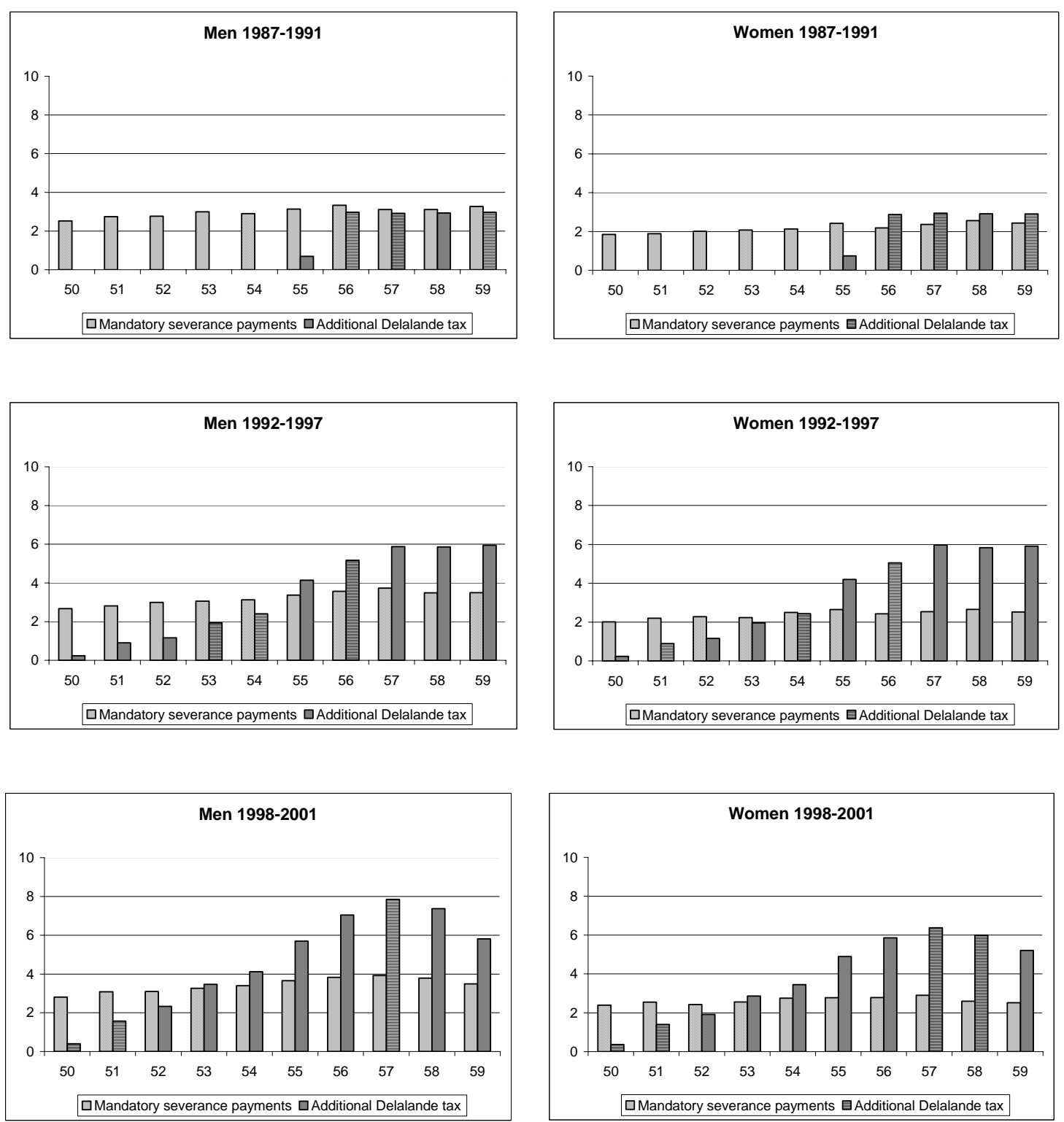

Source: Enquête Emploi, 1987-2001

Note : At each age, the bar displays the mandatory severance payments paid by the firm to the worker, plus the Delalande tax paid to the unemployment insurance system.

As mandatory severance payments depend on the seniority of the worker, and as the Delalande cost sometimes depend on the size of the firm, average costs are computed for each age group using the distribution of seniority and firm size from the Enquête Emploi. 
Figure 2: Layoff rates according to age and to the period

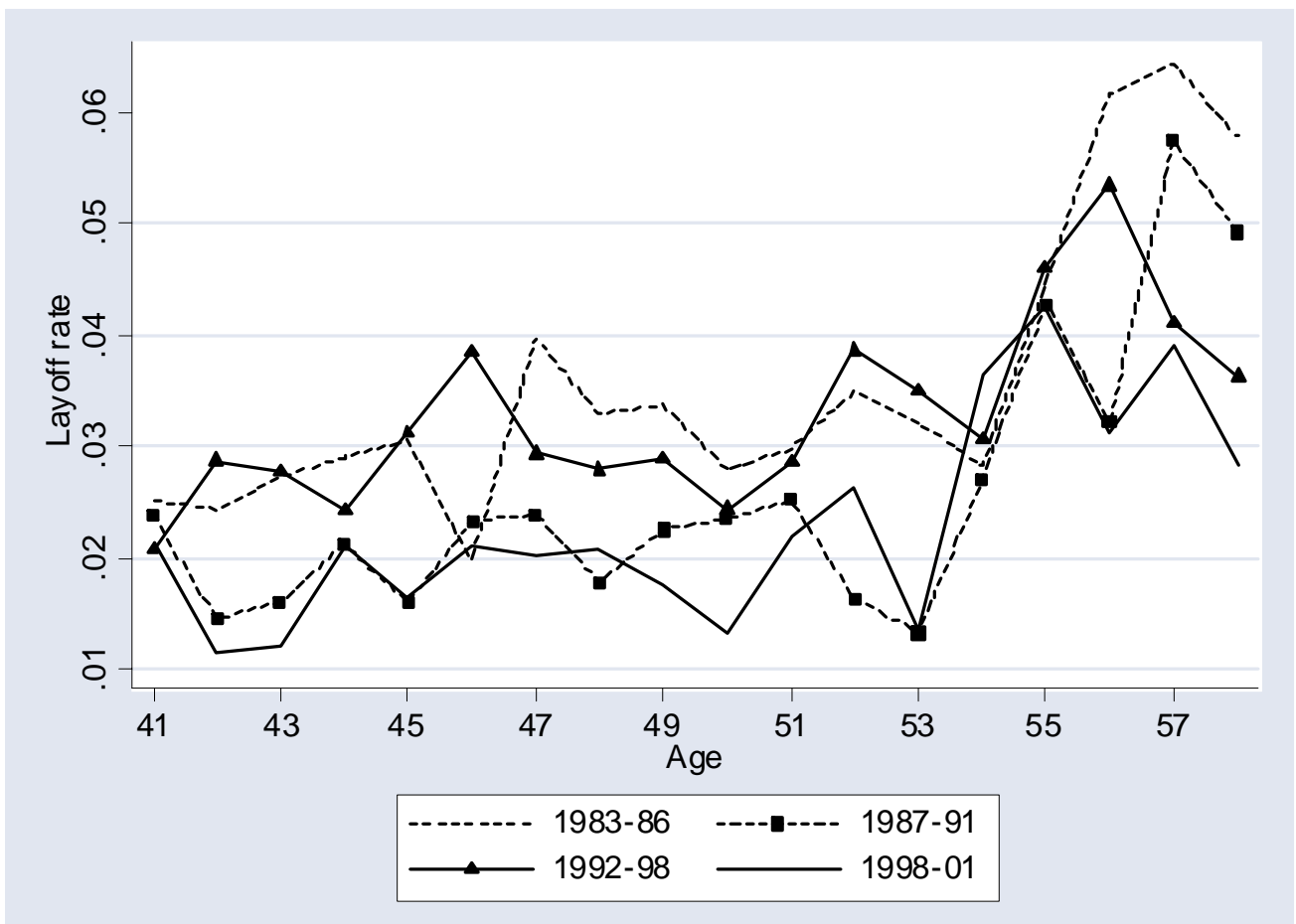

Source: Enquête Emploi, 1983-2001

Note : Layoff rates are computed from yearly transitions for each age group. 


\section{Figure 3: Yearly rate of transition from unemployment to employment under indefinite duration contract (men)}
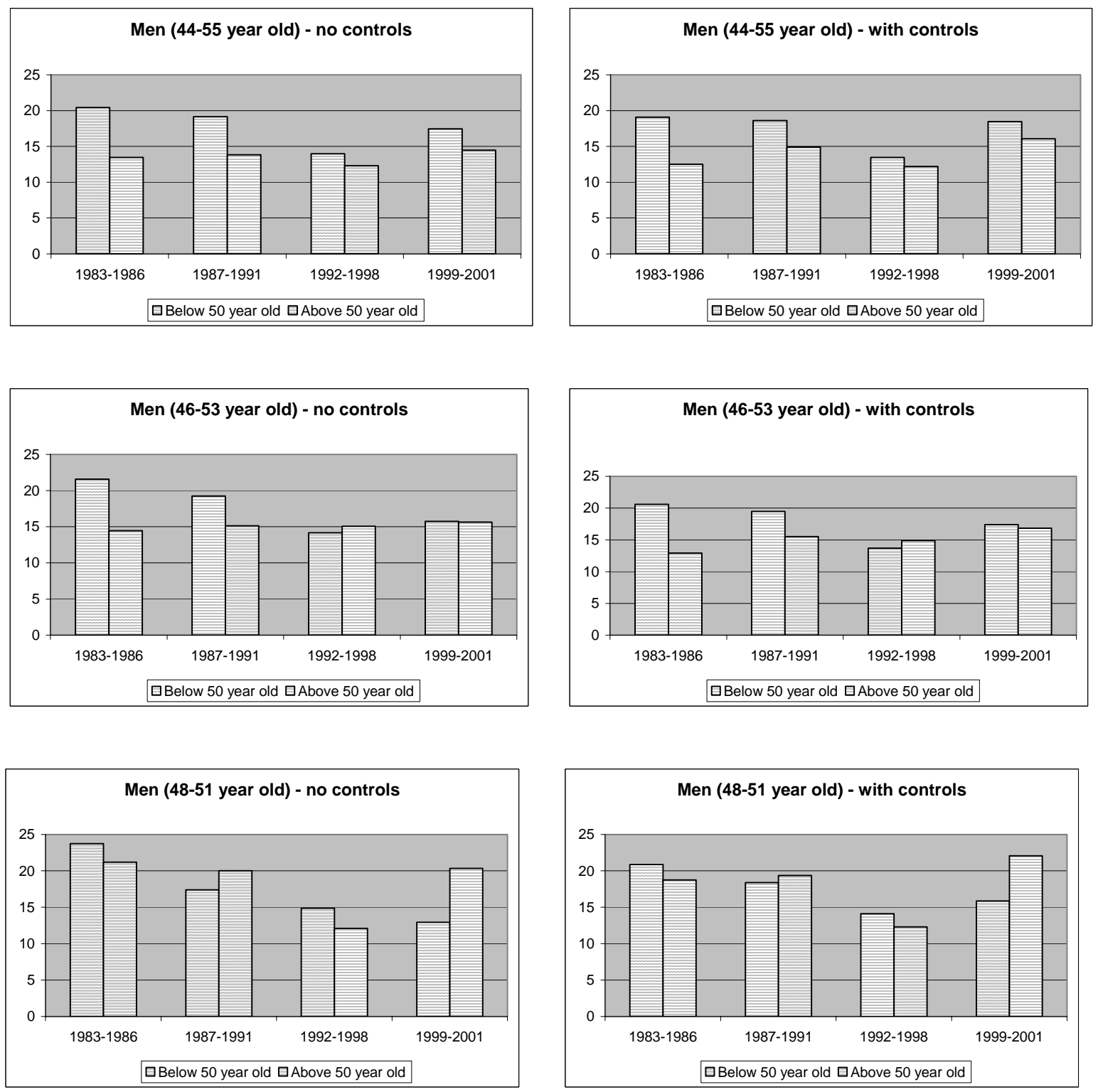

Source: Enquête Emploi, 1983-2001

Note : For each period, the bars display yearly transition rates from unemployment to employment under indefinite duration contracts, for two age groups: below and above 50 year old. Graphics on the different lines use different age windows (from the top: 44-55 year old, 46-53 year old and 48-51 year old). Graphics on the left display simple means. Graphics on the right control for changes across periods and age in the composition of the groups (linear probability model). The control variables are: unemployment duration, industry and occupation in previous job, education level, rural or urban place of residence, family situation. 


\section{Figure 4: Yearly rate of transition from unemployment to employment, women}
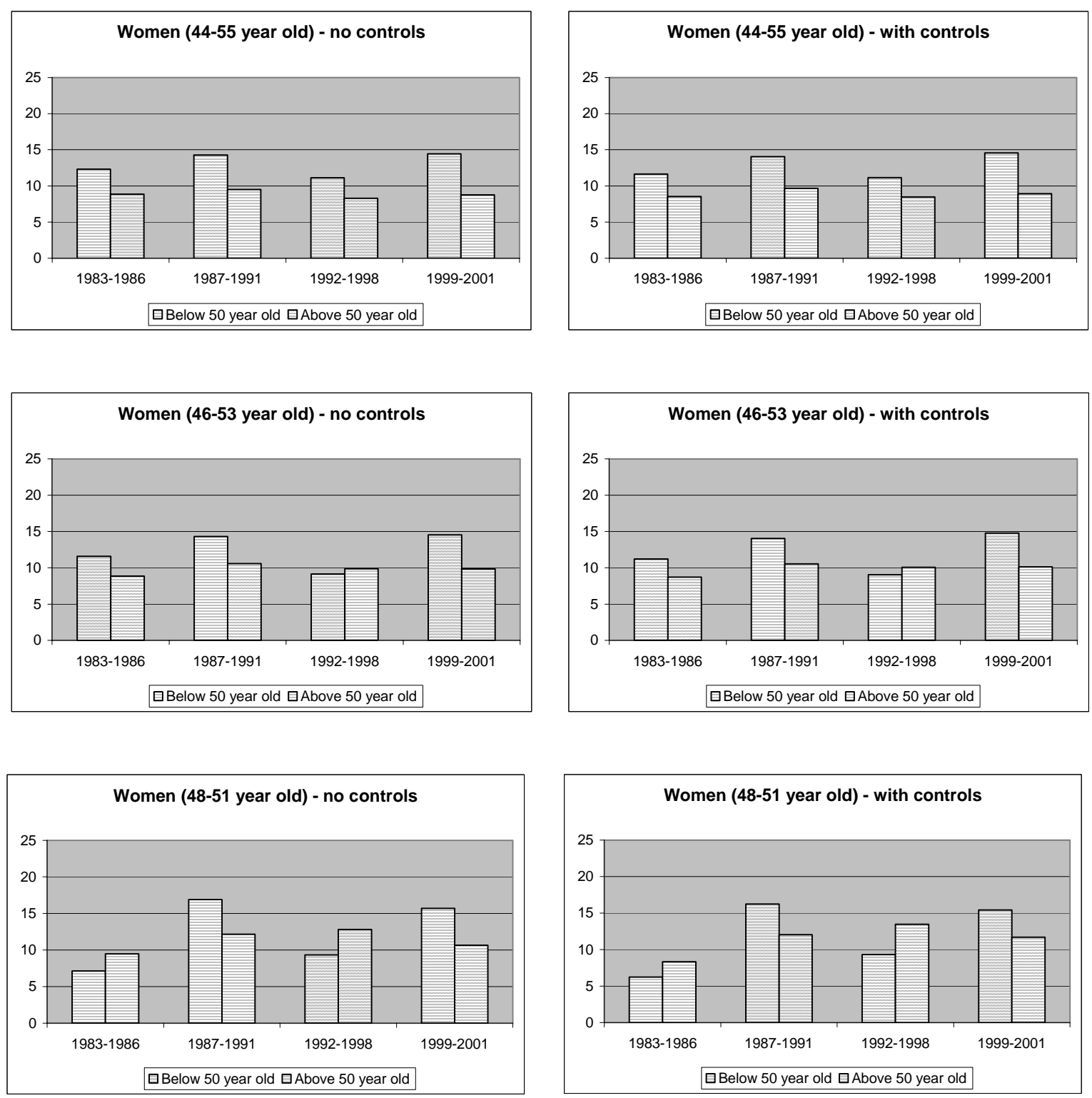

Source: Enquête Emploi, 1983-2001

Note : For each period, the bars display yearly transition rates from unemployment to employment under indefinite duration contracts, for two age groups: below and above 50 year old. Graphics on the different lines use different age windows (from the top: 44-55 year old, 46-53 year old and 48-51 year old). Graphics on the left display simple means. Graphics on the right control for changes across periods and age in the composition of the groups (linear probability model). The control variables are: unemployment duration, industry and occupation in previous job, education level, rural or urban place of residence, family situation. 
Figure 5: Predicted yearly layoff rates with and without the Delalande tax

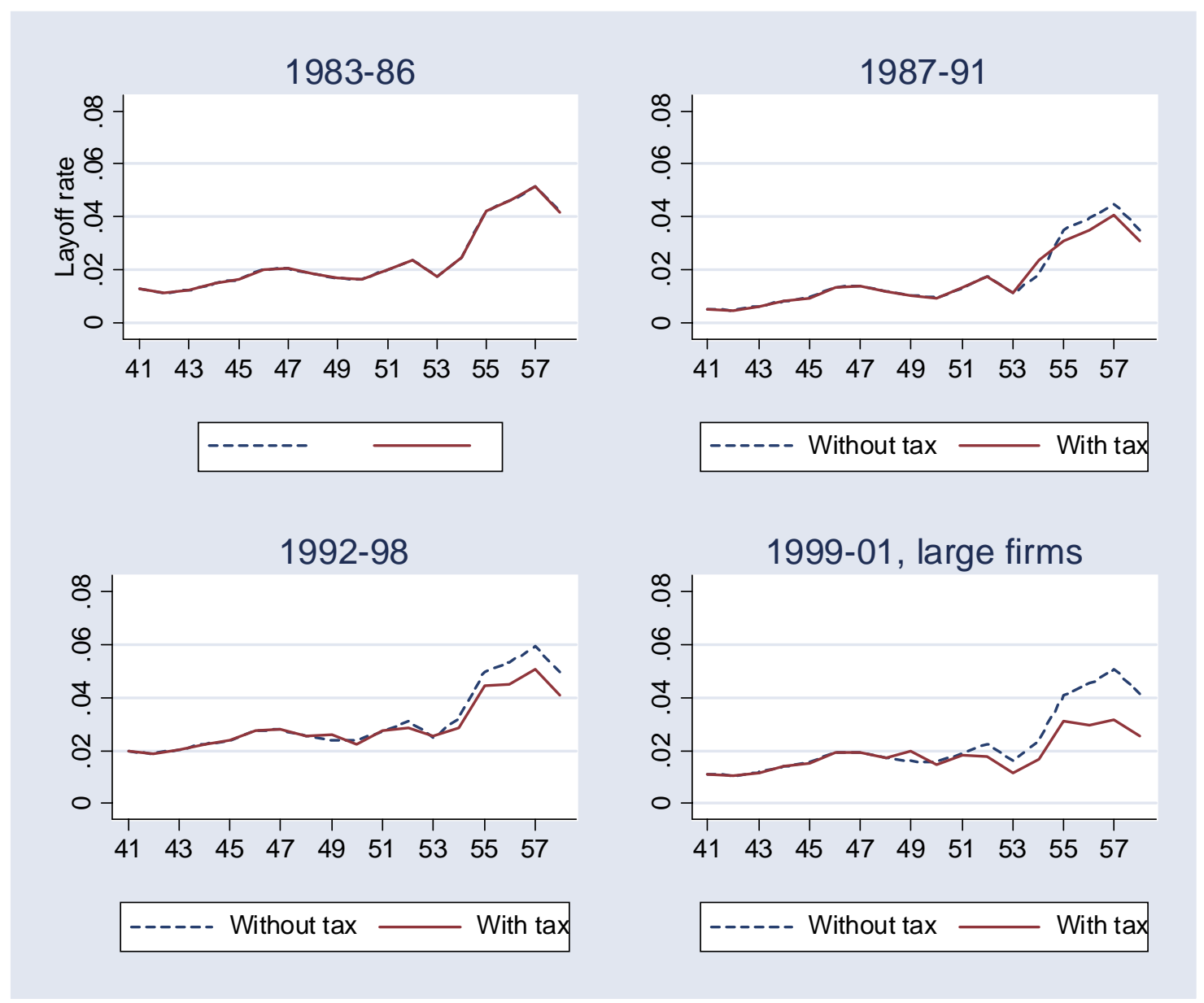

Source: Enquête Emploi, 1983-2001

Note : For each period, the dashed line displays the predicted layoff rate without Delalande tax, and the full line displays the predicted layoff rate with the additional Delalande cost. Predictions are using estimates of column 3 in table 9, to which we apply the Delalande schedule. See note to table 9 for more details. 